\title{
SUBSTITUIÇÃO DO CIMENTO PORTLAND POR RESÍDUO DE PLACA CERÂMICA EM ARGAMASSA
}

\author{
Micheli Warmling Formigoni ${ }^{\prime}$ \\ Daiane dos Santos da Silva Godinho ' \\ Eduardo Junca ${ }^{2}$ \\ Elaine Guglielmi Pavei Antunes '
}

\section{Resumo}

O objetivo deste trabalho é estudar a substituição do cimento Portland por resíduo de placa cerâmica em argamassa. O resíduo de placa cerâmica foi cominuído e caracterizado através de análise química e análise granulométrica. Em seguida, foram confeccionadas misturas com substituições de 5\%, $12 \%$ e $20 \%$ do cimento Portland e determinados os índices de consistência, absorção da água, índice de vazios, massa específica, resistências à tração na flexão e resistência compressão axial para cada mistura. Os resultados mostraram que o resíduo de placa cerâmica é composto principalmente por $\mathrm{SiO}_{2}$ $(69,09 \%)$ e $\mathrm{Al}_{2} \mathrm{O}_{3}$ (I5,4\%). A substituição de 5 e $12 \%$ ocasionou uma diminuição da porosidade dos corpos de prova. Os testes de resistência à tração na flexão mostraram um aumento nesta propriedade. Entretanto, os testes de resistência à compressão axial apresentaram um decréscimo de 0,9\% e 2,5\% para as substituições de 5 e $12 \%$.

Palavras-chave: Resíduos de placas cerâmicas; Cimento Portland; Resíduos sólidos.

\section{REPLACEMENT OF PORTLAND CEMENT FOR CERAMIC PLATES WASTES IN MORTAR}

\begin{abstract}
The aim of this paper is to study the replacement of Portland cement by ceramic plates waste into mortar. The ceramic plate waste was milled and characterized through chemical analysis and particle size analysis. Then, it was elaborated mixtures in order to replace 5, 12 and $20 \mathrm{wt}$.\% of Portland cement by ceramic plates waste. In addition, the consistency indices, water absorption, void index, specific mass, tensile strength in flexion and axial compression were determined for each mixture. The results showed that the ceramic plates waste are composed by of $\mathrm{SiO}_{2}(69.09 \mathrm{wt} . \%)$ and $\mathrm{Al}_{2} \mathrm{O}_{3}(\mathrm{I} 5.4 \mathrm{wt} . \%)$. The replacement of 5 and $12 \mathrm{wt}$.\% decreased the mortar porosity. The tensile strength in flexion assays showed an increase on this property. However, the axial compression tests presented a decrease of $0.9 \%$ and $2.5 \%$ for replacement of 5 and $12 \mathrm{wt} . \%$.
\end{abstract}

Keywords: Ceramic plate waste; Portland cement; Solid waste.

\section{INTRODUÇÃO}

O consumo elevado de cimento gera, por consequência, uma demanda de produção maior. Conforme Melo [I], essa elevação do consumo de cimento Portland provoca problemas ambientais, por sua produção possuir um alto consumo de energia e matéria-prima, sendo responsável por cerca de 5 a $7 \%$ das emissões mundiais de dióxido de carbono, estando assim, diretamente ligado ao efeito estufa e contribuindo para o aquecimento global $[2,3]$. Além do impacto ambiental citado acima, existe também a geração de resíduos sólidos, líquidos e gasosos. Estudos apontam que cerca de $50 \%$ dos resíduos sólidos gerados pelo conjunto de atividades humanas são provenientes da construção civil, sendo estes compostos basicamente por tijolo, vidro, cerâmica e concreto [4].

'Departamento de Engenharia Civil, Universidade do Extremo Sul Catarinense - Unesc, Criciúma, SC, Brasil.

${ }^{2}$ Programa de Pós-graduação em Ciência e Engenharia de Materiais, Universidade do Extremo Sul Catarinense - Unesc, Criciúma, SC, Brasil. E-mail: eduardojunca@unesc.net 
Dentro das possíveis alternativas de reciclagem de resíduos da construção civil, estão os resíduos cerâmicos denominados "chamotes", que é o produto cerâmico argiloso após sofrer queima e com falhas, sendo desclassificado para a venda e utilização. Existem diversos tipos de materiais cerâmicos e com as mais variadas aplicações. Dentro desses diversos tipos, destacam-se os materiais de revestimento, tais como, pisos cerâmicos, porcelanatos e azulejos. Destes, os pisos cerâmicos e porcelanatos são matérias que apresentam excelentes características técnicas, como alta resistência mecânica e abaixa absorção de água [5].

Segundo pesquisa realizada pelo SINDICERAM (Sindicato das Indústrias de Cerâmica - Criciúma - SC) [6], em dezembro de 2015 , o volume produzido de pisos foi de aproximadamente $6.600 .000 \mathrm{~m}^{2}$ e de azulejos foi de $2.000 .000 \mathrm{~m}^{2}$ na região de Criciúma, sendo, portanto, uma região ativa na geração de resíduos cerâmicos. Estes materiais são compostos principalmente por $\mathrm{SiO}_{2}$ e $\mathrm{Al}_{2} \mathrm{O}_{3}$ [7], o que indica a possibilidade de uso como material pozolânico. Desta forma, o objetivo deste trabalho é verificar a viabilidade da utilização do pó de placas cerâmicas queimadas, oriundas do descarte de placas em desconformidade e consideradas impróprias para venda, como substituição parcial do cimento Portland em argamassas.

\section{MATERIAIS E MÉTODOS}

\section{I Caracterização do Resíduo de Placa Cerâmica}

O resíduo utilizado no presente trabalho, consistiu de placas cerâmicas esmaltadas de corpo vermelho, produzida na cidade de Criciúma-SC. Para a fragmentação das mesmas, foi utilizado um britador de mandíbulas. Em seguida, o material foi separado por peneiramento, sendo constituído de $20 \%$ de material passante na peneira USS/ASTM $n^{\circ} 5(4,00 \mathrm{~mm})$ e $80 \%$ de material retido. $O$ material passante na peneira, foi posteriormente moído por mais 45 minutos no moinho periquito e 7 horas no moinho gira-jarro.

Após a moagem, foi realizada a caracterização através de análise química (espectrometria de fluorescência de raios-X e espectrometria de absorção atômica) e análise granulométrica por difração a laser (Particle Size Analyzer Cilas 1064) utilizando água como liquido e poliacrilato de sódio como agente dispersante.

\subsection{Determinação do Índice de Consistência}

Através do ensaio de índice de consistência, foi estabelecida a relação água/aglomerante dos traços em estudo, para posterior moldagem dos corpos de prova. Esta etapa foi realizada de acordo com a norma ABNT NBR I3276:2005 [8]. Em adição, adotou-se uma relação água/aglomerante de $0,88 \mathrm{em}$ todas as misturas.

\subsection{Confecção dos Corpos de Prova}

Foram confeccionadas três misturas visando estudar o efeito da substituição do cimento Portland pelo resíduo de placas cerâmicas, além de uma mistura de referência (sem resíduo). As misturas foram preparadas com a substituição $5 \%, 12 \%$ e $20 \%$ de cimento Portland pelo pó de placa cerâmica. A tabela I mostra a proporção (em volume) de cada insumo, onde CP0 é a mistura de referência; CP5, CPI2 e CP20 indicam a substituição de cimento Portland por 5 , 12 e $20 \%$ de resíduo de placas cerâmicas, respectivamente.

A mistura de referência foi confeccionada com a relação cimento:cal:areia:resíduo de $1: 0,25: 5,5$. Em adição, foi utilizada nas misturas o cimento CPIV-32, areia média com finura de 2,05 e cal hidratada.

\subsection{Determinação da Absorção da Água, Índice de Vazios e Massa Específica}

Foram moldados 2 corpos de prova cilíndricos para cada traço, com $5 \mathrm{~cm}$ de diâmetro e $10 \mathrm{~cm}$ de altura, de acordo com a ABNT NBR 72 15: 1996 [9]. A cura foi realizada ao ar durante 24 horas, sendo, em seguida, imerso em tanque com água saturada de cal, onde permaneceram até o momento do ensaio, com um total de 20 dias de cura.

O ensaio de absorção de água $(A)$ foi realizado de acordo com a norma ABNT NBR 9778:2005 [ [ 10]. Para se obter a massa no estado seco $\left(\mathrm{m}_{\mathrm{s}}\right)$, a amostra foi mantida em estufa a $105^{\circ} \mathrm{C}( \pm 5)$ por 72 horas. Em seguida, foi determinada a massa na condição saturada $\left(\mathrm{m}_{\mathrm{sat}}\right)$ dos corpos de prova, onde ao ser retirada da estufa, os mesmos foram imersos em água a $23^{\circ} \mathrm{C}( \pm 2)$ por um período de 72 horas. Assim, a absorção de água pode ser calculada pela equação I.

$$
A=\frac{\mathrm{m}_{\text {sat }}-\mathrm{m}_{\mathrm{s}}}{\mathrm{m}_{\text {sat }}}
$$

Para se obter o índice de vazios $I_{v}$, após a determinação da massa saturada, os corpos de prova foram colocados em um recipiente cheio de água, que foi progressivamente levada à ebulição, por um período de 5 horas, com volume aproximadamente constante. Após a fervura, a água foi resfriada lentamente até a temperatura de $23^{\circ} \mathrm{C}( \pm 2)$. A massa do corpo de prova após este procedimento é a

Tabela I. Proporção dos insumos utilizados na confecção dos corpos de prova

\begin{tabular}{cc}
\hline Mistura & Composição* \\
\hline CP0 & I:0,25:5,5:0 \\
CP5 & $0,95: 0,25: 5,5: 0,05$ \\
CPI2 & $0,88: 0,25: 5,5: 0,12$ \\
CP20 & $0,80: 0,25: 5,5: 0,20$ \\
\hline
\end{tabular}

*Relação: cimento:cal:areia:resíduo. 
massa saturada em água $\left(\mathrm{m}_{\mathrm{i}}\right)$. Desta forma, o índice de vazios pode ser obtido através da equação 2 .

$$
I_{v}=\frac{m_{s a t}-m_{s}}{m_{\text {sat }}-m_{i}}
$$
equação 3 .

Já a massa específica seca $\left(\rho_{\mathrm{s}}\right)$ foi determinada pela

$$
\rho_{s}=\frac{m_{s}}{m_{s a t}-m_{i}}
$$

\subsection{Resistência à Tração na Flexão}

O ensaio de resistência à tração na flexão foi realizado de acordo com a ABNT NBR 13279:2005 [I I]. Foram moldados 3 corpos de prova prismáticos, com dimensões de $4 \mathrm{~cm} \times 4 \mathrm{~cm} \times 16 \mathrm{~cm}$ e curados na temperatura de $23^{\circ} \mathrm{C}$ $( \pm 2)$ e umidade relativa de $60 \%( \pm 5)$ durante 28 dias. Foi aplicada uma carga de $50 \mathrm{~N} / \mathrm{s}( \pm 10)$ até a ruptura do corpo de prova. A resistência à tração $\left(R_{f}\right)$ foi calculada segundo a equação 4 .

$$
R_{f}=\frac{1,5 \times F_{f} \times L}{40^{3}}
$$

Sendo $F_{f}$ a carga vertical no centro do prisma, em newtons $(\mathrm{N})$, e $\mathrm{L}$ a distância entre os suportes, em milímetros.

\subsection{Resistência à Compressão Axial}

Os testes de resistência à compressão axial $\left(R_{c}\right)$ foram realizados de acordo com a ABNT NBR 13279:2005 [I I]. Nestes testes, foram utilizadas as metades dos três corpos de prova do ensaio de resistência à tração na flexão. Foi aplicada uma carga de $500 \mathrm{~N} / \mathrm{s}( \pm 50)$ até a ruptura de cada corpo de prova. A resistência à compressão axial $(\mathrm{Rc})$ é calculada segundo a equação 5 .

$$
R_{c}=\frac{F_{c}}{1600}
$$

Onde $F_{c}$ é a carga máxima aplicada, em newtons; 1600 é a área da seção considerada quadrada do dispositivo de carga $40 \mathrm{~mm} \times 40 \mathrm{~mm} \times 16 \mathrm{~mm}$, em milímetros quadrados.

\subsection{Absorção de Água por Capilaridade e Coeficiente de Capilaridade}

Os testes de absorção de água por capilaridade $\left(\mathrm{A}_{t}\right)$ foram realizados de acordo com a ABNT NBR I5259:2005 [I 2]. Para esse ensaio, foram usados 3 corpos de prova prismáticos moldados conforme a NBR I 3279 [I I], com dimensões de $4 \mathrm{~cm} \times 4 \mathrm{~cm} \times 16 \mathrm{~cm}$. A cura foi de 28 dias com a temperatura de $23^{\circ} \mathrm{C}( \pm 2)$ e umidade relativa de $60 \%( \pm 5)$. Após a cura, os corpos de prova foram pesados $\left(m_{0}\right)$. Em seguida, os corpos de prova foram posicionados com as faces quadradas sobre o suporte no recipiente de ensaio, onde o nível de água permaneceu constante a $5 \mathrm{~mm}( \pm \mathrm{I})$ acima da face em contato com a água. A massa de cada corpo de prova foi determinada após 10 minutos $\left(m_{10}\right)$ e 90 minutos $\left(m_{90}\right)$ de imersão, respectivamente. $A$ absorção de água por capilaridade foi calculada pela equação 6 .

$$
A_{t}=\frac{m_{t}-m_{0}}{16}
$$

Sendo $m_{t}$ a massa do corpo de prova em cada tempo, em gramas; $m_{0}$ a massa inicial do corpo de prova, em gramas; t corresponde os tempos de 10 e 90 minutos, em segundos; e 16 é a área do corpo de prova, em centímetros quadrados.

Em adição, o coeficiente de capilaridade foi calculado de acordo com a equação 7 .

$$
C=m_{90}-m_{10}
$$

\section{RESULTADOS E DISCUSSÕES}

\section{I Caracterização do Resíduo de Placas Cerâmicas}

A tabela 2 mostra que o resíduo de placas cerâmicas é composto principalmente por $\mathrm{SiO}_{2}(69,09 \%)$ e $\mathrm{Al}_{2} \mathrm{O}_{3}$ $(15,40 \%)$, que são os principais componentes de pozolanas naturais $[13,14]$.

A análise granulométrica mostrou que $100 \%$ das partículas são menores que $100 \mu \mathrm{m}, 90 \%$ das partículas são menores que $26 \mu \mathrm{m}$ e $50 \%$ são menores que $5,5 \mu \mathrm{m}$, indicando que a faixa granulométrica do resíduo está de acordo com a granulometria para um material pozolana, onde segundo a norma ABNT NBR I2653:2012 [14, I5], no máximo $34 \%$ das partículas do material podem estar acima de $45 \mu \mathrm{m}$.

\subsection{Absorção de Água, Índice de Vazios e Massa Específica}

Os resultados de absorção de água, índice de vazios e massa específica são apresentados na tabela 3 .

Tabela 2. Composição química do resíduo de placas cerâmicas

\begin{tabular}{cc}
\hline Compostos & Teor (\%) \\
\hline $\mathrm{SiO}_{2}$ & 69,09 \\
$\mathrm{Al}_{2} \mathrm{O}_{3}$ & 15,40 \\
$\mathrm{~K}_{2} \mathrm{O}$ & 4,72 \\
$\mathrm{Fe}_{2} \mathrm{O}_{3}$ & 4,24 \\
$\mathrm{MgO}$ & 2,28 \\
$\mathrm{Na}_{2} \mathrm{O}$ & 1,59 \\
$\mathrm{CaO}$ & 0,97 \\
$\mathrm{TiO}_{2}$ & 0,57 \\
Perda ao fogo & 0,57 \\
\hline
\end{tabular}


Tabela 3. Valores médios de absorção de água, índice de vazios e massa específica para argamassas contendo resíduo de placas cerâmicas

\begin{tabular}{cccc}
\hline Mistura & A & Iv & $\rho_{\mathrm{s}}$ \\
\hline CP0 & 10,58 & 21,18 & 2,00 \\
CP5 & 10,55 & 21,05 & 1,99 \\
CPI2 & 10,57 & 21,12 & 2,00 \\
CP20 & 10,83 & 21,37 & 1,97 \\
\hline
\end{tabular}

Nota-se que os traços CP5 e CPI 2 apresentaram um decréscimo na absorção de água de 0,28 e 0,09\% comparado com o CPO. Além disso, foi observado o mesmo comportamento para o índice de vazios e da massa específica.

$\mathrm{O}$ traço $\mathrm{CP} \mid 2$ apresentou uma redução na absorção de água e no índice de vazios, enquanto que a massa específica permaneceu constante ao CPO. Em adição, o traço CP20 apresentou um aumento na absorção de água $(2,37 \%)$ e no índice de vazios $(0,90 \%)$. O aumento da porosidade também pode ser comprovado levando em consideração o resultado da massa específica $\left(\rho_{\mathrm{s}}\right)$ para o traço CP20. Para esta mistura, o valor de $\rho_{s}$ foi o menor $(1,97)$, indicando um maior volume de poros, o que causa uma maior absorção de água, conforme indicam os resultados. Além disso, a substituição de 5 e $10 \%$ de cimento por resíduo de placas cerâmicas produziram argamassas com maior porosidade quando comparada à argamassa referencia (CPO). Para substituição de $20 \%$ houve um aumento da porosidade da argamassa em relação ao $\mathrm{CPO}$.

\subsection{Absorção de Água por Capilaridade e Coeficiente de Capilaridade}

O resultado de absorção de água por capilaridade pode ser visto na figura $I$.

A mistura CPO apresentou uma absorção de água por capilaridade de $0,256 \mathrm{~g} / \mathrm{cm}^{2}$. A substituição de cimento por resíduo de placas cerâmicas diminuiu a absorção de água por capilaridade para as misturas CP5 e CPI 2 em 9\% e 6\%, respectivamente, para o tempo de 10 minutos. Para a mistura CP20 houve um acréscimo na absorção de água por capilaridade em $8 \%$ para o mesmo tempo. O mesmo efeito foi observado para o tempo de 90 minutos. Para este teste, a mistura CPO apresentou um valor de $0,733 \mathrm{~g} / \mathrm{cm}^{2}$. As misturas CP5 e CPI 2 apresentaram uma diminuição deste índice em $7 \%$ e $2 \%$, respectivamente, enquanto que para a mistura CP20 houve um acréscimo de $16 \%$ na absorção de água por capilaridade. Tais resultados indicam que a substituição de 5 e $12 \%$ de cimento por resíduo de placas cerâmicas diminuem a porosidade dos corpos de prova, conforme foi mostrado na tabela 3.

Em contrapartida, para a mistura contendo $20 \%$ de resíduo houve um aumento da porosidade do corpo de prova.

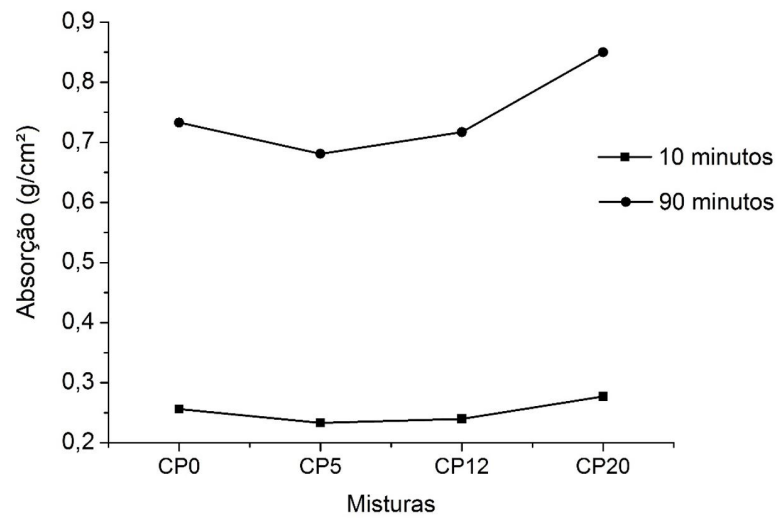

Figura I. Absorção de água por capilaridade obtidos para diferentes valores de resíduo de placas cerâmicas.

\subsection{Coeficientes de Capilaridade, Resistência à Tração na Flexão e Resistência à Compressão Axial}

A figura 2 mostra os resultados dos coeficientes de capilaridade, resistência a tração na flexão e resistência à compressão axial para cada mistura.

Com relação ao coeficiente de capilaridade, a norma ABNT NBR 13281:2005 [16] classifica o coeficiente de capilaridades obtidos neste trabalho na classe $\mathrm{C} 5$, com coeficientes entre 5 a $12 \mathrm{~g} / \mathrm{dm}^{2} \cdot \mathrm{min}^{1 / 2}$.

Com relação a resistência à tração na flexão, observou-se que as misturas $\mathrm{CP} 5$ e CPI 2 apresentaram um aumento de $8,9 \%$ e $13,9 \%$, respectivamente, na resistência à tração na flexão, em relação ao traço referência CP0 (3,02 MPa). Por outro lado, a substituição de $20 \%$ do cimento por resíduo de placas cerâmicas promoveu uma queda de $0,6 \%$ na resistência à tração na flexão. Este comportamento também está ligado à porosidade dos corpos de prova. $\mathrm{O}$ aumento da porosidade sugere uma menor resistência a tração na flexão.

Os testes de resistência à compressão axial mostram que houve um decréscimo de $0,9 \%, 2,5 \%$ e $10 \%$ para as misturas $C P 5, C P 12$ e CP20, respectivamente, em relação a mistura de referência (CPO). Tal fato pode ter ocorrido devido à manutenção da relação água/aglomerante de 0,88 em todas as misturas. Assim, com o aumento do teor de resíduo na composição da mistura, e consequente diminuição do teor de cimento, proporcionou um aumento da relação água/cimento, o que causa a diminuição da resistência da mistura $[17,18]$. 


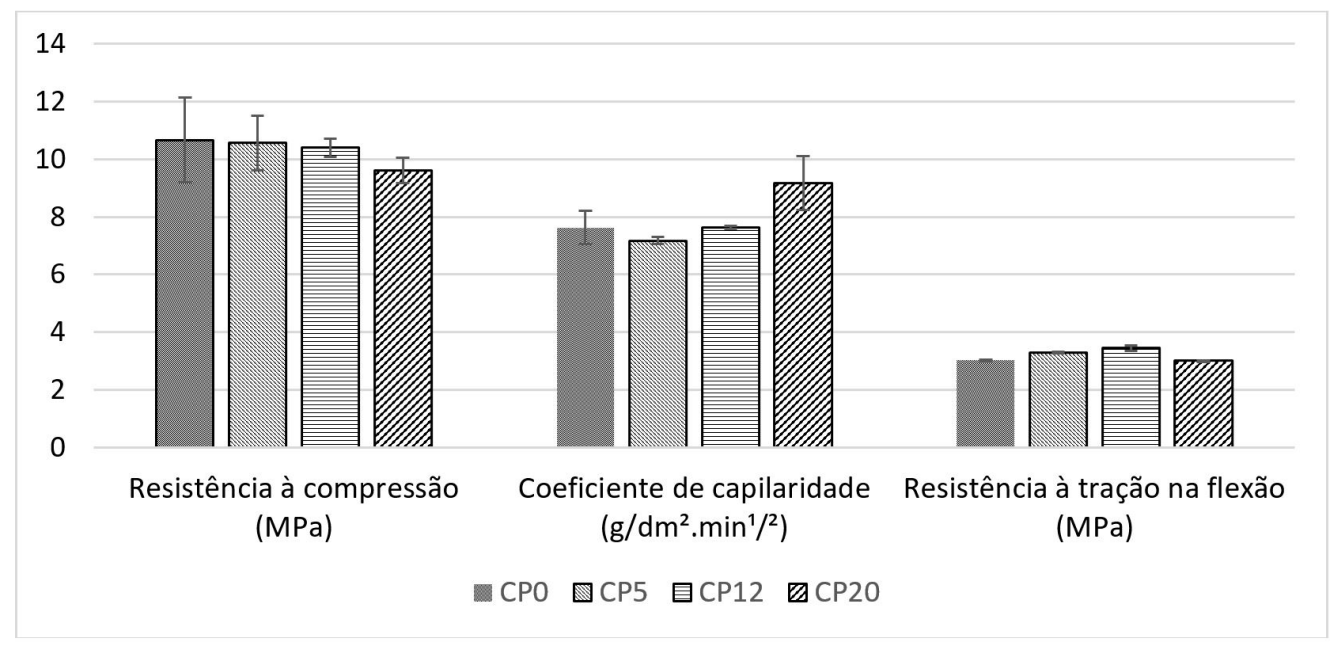

Figura 2. Influência da substituição do cimento por resíduo de placas cerâmicas no coeficiente de capilaridade do corpo de prova para cada argamassa.

\section{CONCLUSÕES}

A partir dos resultados, conclui-se que o resíduo de placa cerâmica é composto principalmente por $\mathrm{SiO}_{2}(69,09 \%)$ e $\mathrm{Al}_{2} \mathrm{O}_{3}(15,40 \%)$ o que possibilita a substituição parcial do cimento por este resíduo. Com relação às características físicas da argamassa, a substituição de 5 e $12 \%$ (em massa) do cimento pelo resíduo ocasionou um menor volume de poros nos corpos de prova. Por consequência, um aumento na resistência a tração de $8,9 \%$ e $13,9 \%$, para as amostras $\mathrm{CP} 5$ e CPI2, respectivamente, foram obtidas. Por outro lado, houve um decréscimo de apenas $0,9 \%$ e 2,5\% nos testes de resistência à compressão axial. Portanto, a substituição de 5 e $12 \%$ do cimento pelo resíduo apresentaram resultados promissores, indicando a possibilidade de uso sem perdas acentuadas em propriedades físicas da argamassa.

\section{Agradecimentos}

Os autores agradecem a Universidade do Extremo Sul Catarinense.

\section{REFERÊNCIAS}

I Melo FCAC. Analise de Argamassas com substituição Parcial do Cimento Portland por Cinza Residual de Lenha de Algaroba [dissertação]. Natal: Programa de Pós-graduação em Engenharia Civil, Universidade Federal do Rio Grande do Norte; 2012.

2 Ebrahimi A, Saffari M, Milani D, Montoya A, Valix M, Abbas A. Sustainable transformation of fly ash industrial waste into a construction cement blend via CO2 carbonation. Journal of Cleaner Production. 2017;156:660-669.

3 Chen W, Hong J, Xu C. Pollutants generated by cement production in China, their impacts, and the potential for environmental improvement. Journal of Cleaner Production. 20I5;103:6I-69.

4 Andrés R, Salazar R, Rivera JF, Gutiérrez RM. Alkali-activated building materials made with recycled construction and demolition wastes. Construction \& Building Materials. 2017;149:130-138.

5 Paixão C, Caetano A, Coliante LF, Silva JGR, Bergmann LCP, Carlos P. Estudo da viabilidade de utilização de resíduos cerâmicos para confecção de argamassas. Cerâmica Industrial. 20I I;4:33-38.

6 Sindicato das Industrias de Cerâmica de Criciúma - SINDICERAM. [página da internet]. [acesso em I5 Fev. 20I9]. Disponível em: <http://www.sindiceram.com.br/dados-do-setor >.

7 Elçi H. Utilisation of crushed floor and wall tile wastes as aggregate in concrete production. Journal of Cleaner Production. 2016; I 12:742-752.

8 Associação Brasileira de Normas Técnicas - ABNT. NBR 13276: Argamassa para assentamento e revestimento de paredes e tetos - Requisitos. Rio de Janeiro: ABNT; 2005.

9 Associação Brasileira de Normas Técnicas - ABNT. NBR 7215: Cimento Portland - Determinação da resistência à compressão. Rio de Janeiro: ABNT; 1996. 
10 Associação Brasileira de Normas Técnicas - ABNT. NBR 9778: Argamassa e concreto endurecidos - Determinação da absorção de água, índice de vazios e massa específica. Rio de Janeiro: ABNT; 2005.

II Associação Brasileira de Normas Técnicas - ABNT. NBR 13279: Argamassa para revestimento de paredes e tetos Determinação da resistência à tração na flexão e à compressão. Rio de janeiro: ABNT; 2005.

12 Associação Brasileira de Normas Técnicas - ABNT. NBRI5259: Argamassa para assentamento e revestimento de paredes e tetos - Determinação da absorção de água por capilaridade e do coeficiente de capilaridade. Rio de Janeiro: ABNT; 2005.

13 Belaidi ASE, Azzouz L, Kadri E, Kenai S. Effect of natural pozzolana and marble powder on the properties of selfcompacting concrete. Construction \& Building Materials. 20I2;3I:25I-257.

14 Al-Swaidani A, Hammoud I, Meziab A. Effect of adding natural pozzolana on geotechnical properties of limestabilized clayey soil. Journal of Rock Mechanics and Geotechnical Engineering. 2016;8:714-725.

15 Associação Brasileira de Normas Técnicas - ABNT. NBRI 2653: Materiais pozolânicos - Requisitos. Rio de Janeiro: Associação Brasileira de Normas Técnicas - ABNT; ABNT; 2012.

16 Associação Brasileira de Normas Técnicas - ABNT. NBRI328I: Argamassa para assentamento e revestimento de paredes e tetos - requisitos. Rio de janeiro: ABNT; 2005.

17 Haach VG, Vasconcelos G, Lourenco PB. Influence of aggregates grading and water/cement ratio in workability and hardened properties of mortars. Construction \& Building Materials. 201 I;25:2980-2987.

I8 Singh SB, Munjal P, Thammishetti N. Role of water/cement ratio on strength development of cement mortar. Journal of Building Engineering. 2015;4:94- 100.

Recebido em: 12 Dez. 2017

Aceito em: 12 Jul. 2018 